\title{
Agregação de dinâmicas heterogêneas, acurácia da meia-vida e o enigma da PPC: evidência para cidades brasileiras
}

\author{
Felipe Sousa Bastos ${ }^{1}$ \\ Roberto Tatiwa Ferreira ${ }^{2}$
}

\section{Resumo}

O enigma da PPC é apontado como um dos seis mais importantes puzzles da macroeconomia internacional. IMRR (2005a) apontam o viés de agregação de preços com dinâmica de ajuste heterogêneo como solução para o enigma. Este trabalho averigua se esse resultado é suportado para dados de cidades brasileiras utilizando-se o estimador CCEMG dinâmico, proposto por Chudik e Pesaran (2015), com correção half-panel jackknife para o viés do estimador OLS em amostra pequena. Os resultados corroboram a evidência de IMRR (2005a), com uma meia-vida mediana de 13,5 meses.

\section{Palavras-Chave}

Viés de Heterogeneidade. Meia-vida. Enigma da PPC.

\begin{abstract}
The PPP puzzle is named as one of six major puzzles in international macroeconomics. IMRR (2005a) point out to the aggregation bias of price with heterogeneous adjustment dynamics as a solution to the puzzle. This paper investigates whether this result is supported for Brazilian cities data using a dynamic CCEMG estimator with half-panel jackknife bias correction to mitigate the small sample time series bias proposed by Chudik and Pesaran (2015). The results corroborate the IMRR's (2005a) evidence, with a median half-life of 13.5 months.
\end{abstract}

\section{Keywords}

Aggregation Bias. Half-life. PPP Puzzle.

\section{JEL Classification}

C32. F31. F47.

1 Professor - Universidade Federal do Ceará - Campus Sobral (CAEN/UFC)

End.: Avenida da Universidade, 2700 - $2^{\circ}$ Andar - Benfica - Fortaleza/CE - Brasil - CEP 60020-181

E-mail: felipebastos@caen.ufc.br - ORCiD: https://orcid.org/0000-0001-5598-2935.

2 Professor - Universidade Federal do Ceará - Faculdade de Economia, Administração, Atuária e Contabilidade - End.: Avenida da Universidade, 2700 - $2^{\circ}$ Andar Benfica - Fortaleza/ CE - Brasil. CEP: 60020-181 - E-mail: rtf2@uol.com.br - ORCiD: https://orcid.org/0000-0002-2529-686X. Recebido: 10/05/2019. Aceite: 28/02/2020.

Editor Responsável: Dante Mendes Aldrighi

(c) (i) (\$) Esta obra está licenciada com uma Licença Creative Commons Atribuição-Não Comercial 4.0 Internacional. 


\section{Introdução}

A hipótese da Paridade do Poder de Compra (PPC) define uma relação entre os níveis de preços nacionais e a taxa de câmbio. Esta hipótese é fundamento de uma série de modelos voltados para a macroeconomia internacional. Entre eles, pode-se citar o modelo Overshooting de Dornbusch (1976). A PPC tem sua origem na Lei do Preço Único (LPU), a qual afirma que, satisfeitas certas condições, ${ }^{1}$ dois bens idênticos comercializados em mercados concorrentes devem ter o mesmo preço quando expressos em mesma moeda. Caso existam diferenças de preços, operações de arbitragem garantirão a equalização dos preços dentro de um intervalo de tempo. De acordo com Simões e Marçal (2012), esta relação pode ser sintetizada através da seguinte equação:

$$
q_{t}(i)=q_{t}^{*}(i)+s_{t}
$$

na qual $q_{t}(i)$ é o logaritmo neperiano em $t$ do preço doméstico do produto $i, q_{t}^{*}(i)$ é o logaritmo neperiano em $t$ do preço internacional do produto $i$ e $s_{t}$ é o logaritmo neperiano em $t$ da taxa nominal de câmbio entre as duas economias. A PPC é construída a partir da generalização da LPU para uma cesta de mercadorias:

$$
\sum_{i=1}^{N} \omega_{i} q_{t}(i)=\sum_{i=1}^{N} \omega_{i} q_{t}^{*}(i)+s_{t}
$$

em que $\omega_{i}$ é o peso de cada bem em ambas as cestas, doméstica e estrangeira. Algumas condições devem ser satisfeitas para que o mecanismo de equalização dos preços - a arbitragem - funcione perfeitamente. Entre elas, pode-se mencionar a necessidade de que as cestas que compõem os índices de preços sejam padronizadas, as mercadorias sejam homogêneas, informação perfeita, ausência de restrições ao livro fluxo de mercadorias e custos de transação nulo. Caso contrário, o câmbio se desviará de seu valor de equilíbrio e a PPC valerá apenas no longo prazo. $^{2}$

Ausência e custos de transporte e barreiras tarifárias e não tarifárias ao comércio.

2 Para mais detalhes, ver Simões e Marçal (2012). 
Há uma vasta literatura empírica relacionada à velocidade de reversão à média dos desvios da $\mathrm{PPC}^{3}$ em que se tenta medir o tempo necessário para que o efeito de um choque unitário sobre a taxa de câmbio real se dissipe pela metade. A essa medida, bastante difundida em estudos do campo das Ciências Naturais, dá-se o nome de meia-vida.

Muitos desses estudos têm apontado uma surpreendente regularidade. As meias-vidas observadas se concentram no intervalo de 3 a 5 anos, período de tempo muito elevado para ser explicado por choques monetários e financeiros. Rogoff (1996) definiu esta regularidade como o puzzle da PPC. Desde então, um grande esforço tem sido feito para explicar este enigma, os quais concentram-se na acurácia das estimações, seja do processo autorregressivo necessário para o cálculo da meia-vida, ou da medida de meia-vida propriamente dita.

Os vieses relacionados à estimação do processo autorregressivo podem ocorrer ao se utilizar modelos de painel dinâmico (viés de Nickell), agregação temporal e agregação cross-section de coeficientes heterogêneos, má especificação da ordem do processo autorregressivo, presença de quebra estrutural e não linearidades na velocidade de convergência. A heterogeneidade setorial é apontada por Imbs et al. (2005a) - daqui em diante IMRR (2005a) - e Carvalho e Nechio (2011) como solução para o enigma. Estes pesquisadores apontam que a alta persistência surge por conta da dinâmica heterogênea dos setores que compõem a taxa de câmbio real, reportando uma meia-vida bem abaixo do intervalo-consenso.

Quanto aos problemas relacionados ao cômputo da meia-vida, estudos apontam a existência de distorções quando uma medida aproximada de meia-vida é utilizada para o cálculo da mesma em processos autorregressivos de ordem mais alta, ${ }^{4}$ sobretudo na presença de raiz unitária (Seong, Morshed e Ahn 2006). Adicionalmente, Gadea e Mayoral (2009), baseadas na desigualdade de Jensen, reportam problemas no cálculo da Função Impulso-resposta (IRF, no inglês) usada na maioria dos trabalhos empíricos para o cálculo da meia-vida que provocam uma subestimação da verdadeira meia-vida.

3 Um resumo desta literatura pode ser visto em Bastos, Ferreira e Arruda (2018).
4 Processos autorregressivos de ordem maior que 1. 
Muitas são as fontes de desvios da taxa de câmbio real de seu valor de equilíbrio de longo prazo. Fatores como barreiras comerciais, entraves oriundos de questões burocráticas na construção do sistema de distribuição dos bens comercializados, imperfeições de mercado, custos de transportes, diferenças nas cestas de bens e serviços utilizadas na composição do índice de preços entre países, dentre outros, são apontados como elementos que retardam o ajustamento completo dos preços relativos internacionais.

Para lidar com dados em que estes problemas são de menor importância, uma vertente de estudos relacionados à PPC dedica-se à investigação da convergência de preços relativos em cidades de um mesmo país ou entre nações pertencentes a regiões econômicas com moeda única. Para a economia brasileira, Arruda et al. (2015) usam séries de tempo do Índice de Preços ao Consumidor Amplo (IPCA) para as regiões metropolitanas (RMs) brasileiras usadas na construção do índice e reportam uma meia-vida média de 27 meses. Com os mesmos dados, mas em uma estrutura de dados em painel, Bastos, Ferreira e Arruda (2018) reportam uma meia-vida mediana de aproximadamente 38 meses, dentro do intervalo-consenso.

É importante destacar que, em Arruda et al. (2015), não há correção para o viés de pequenas amostras do estimador OLS, nem é dado tratamento adequado ao viés de heterogeneidade setorial apontado por IMRR (2005a). Adicionalmente, o cálculo da meia-vida não é realizado como sugerem Kilian e Zha (2002) e Seong, Morshed e Ahn (2006). Logo, seus resultados devem ser vistos com cautela. Já em Bastos, Ferreira e Arruda (2018), a estimação também não leva em consideração a heterogeneidade setorial, o que pode ser uma fonte de superestimação da meia-vida de convergência dos desvios da PPC.

O exercício proposto neste trabalho, portanto, concentra-se na estimação das meias-vidas de convergência dos desvios da PPC controlada para os vieses provocados pela heterogeneidade setorial e imprecisão da medida de meia-vida aproximada utilizada em processos autorregressivos de ordem mais alta, além da correção para o viés de pequenas amostras do estimador OLS. Para tratar o problema de heterogeneidade na dinâmica de convergência dos setores, utiliza-se o estimador proposto por Chudik e Pesaran (2015). Já para a acurácia da meia-vida, utiliza-se o tratamento proposto por Kilian e Zha (2002), Seong, Morshed e Ahn (2006) e Gadea e Mayoral (2009). Os resultados reforçam aqueles obtidos por IMRR (2005a) e Carvalho e Nechio (2011), com uma meia-vida mediana de aproximadamente 13,5 meses. 
Resultado em conformidade com o previsto em modelos teóricos e substancialmente inferiores aos esforços de cálculo de meia-vida para a economia brasileira realizados por Bastos, Ferreira e Arruda (2018) e Arruda et al. (2015).

Além desta introdução, este trabalho possui mais seis seções. A seguir, descrevem-se os dados utilizados e testa-se a presença de raiz unitária. Na sequência, trata-se a questão da definição adequada da ordem do processo autorregressivo. Em seguida, discute-se o problema de heterogeneidade setorial como uma fonte de viés na estimação dos desvios da PPC. Mais adiante, apresentam-se os resultados e discute-se o problema da acurácia da meia-vida e, por fim, são feitos alguns comentários finais.

\section{Dados e Testes de Raiz Unitária}

Os dados do IPCA foram extraídos do banco de dados do Instituto Brasileiro de Geografia e Estatística (IBGE), compreendendo o período de janeiro de 1991 a dezembro de 2013. ${ }^{5}$ As informações estão desagregadas ao nível de 9 regiões metropolitanas (Belém, Belo Horizonte, Curitiba, Fortaleza, Porto Alegre, Recife, Rio de Janeiro, Salvador e São Paulo) e 2 cidades (Brasília e Goiânia). ${ }^{6}$ Para cada RM, o IPCA está desagregado para as seguintes categorias: alimentação e bebidas, habitação, artigos de residência, vestuário, transportes, saúde e cuidados pessoais, despesas pessoais, educação e comunicação.

É importante frisar que as categorias transportes e comunicação eram computadas como uma única categoria até julho de 1999. Para obtê-las em separado, foi necessário utilizar o IPCA por subgrupo. Já a categoria educação, que não pertencia à rubrica de grupos, é representada pelo subgrupo educação e leitura de janeiro de 1991 a julho de 1999.7

Embora existam observações para o período pós-dezembro de 2013, optou-se por não o considerar por conta da inclusão de Campo Grande e Grande Vitória dentre as áreas amostradas para a estimação do IPCA.

\footnotetext{
5 Algumas observações ausentes foram obtidas por média geométrica.

6 Por economia de notação, tratam-se todas as cidades como região metropolitana.

7 Esses arranjos obedeceram a nota do IBGE.
} 
A sua inclusão implicaria mudanças no peso da participação das RMs no cálculo do índice geral e, como apontam IMRR (2005a), os dados setoriais devem refletir exatamente o índice geral de preços. ${ }^{8}$

Utilizam-se dois tipos de painéis de preços relativos para as RMs brasileiras: um tipo de painel com preços relativos setoriais e outro com preços relativos agregados. Essas medidas podem ser definidas, respectivamente, por:

$$
\begin{aligned}
& q_{i c t}=\ln \left(\frac{I P C A_{i c t}}{I P C A_{i j t}}\right) \\
& q_{c t}=\ln \left(\frac{I P C A_{c t}}{I P C A_{j t}}\right)
\end{aligned}
$$

em que ict refere-se ao indicador para o setor $i$ da região metropolitana $c$ no período $t$. E $j$ refere-se à RM usada como numerário.

Cada uma das RMs é considerada como numerário, uma vez que Papell e Theodoridis (2001) e Chmelarova e Nath (2010) observam que a escolha do numerário é um importante determinante dos resultados de testes de raiz unitária da PPC para painel e, portanto, das meias-vidas de convergência.

Os testes de raiz unitária em painel de Levin, Lin e Chu (2002) - LLC -, Im, Pesaran e Shin (2003) - IPS - e Pesaran (2007) - CIPS - são utilizados para testar a hipótese nula de raiz unitária. A hipótese alternativa $\left(H_{a}\right)$ , para o teste LLC, é de que todas as séries no painel são estacionárias, enquanto que para os testes IPS e CIPS é de que apenas uma fração delas é estacionária. O teste LLC restringe que todas as unidades individuais tenham o mesmo parâmetro autorregressivo. Por outro lado, essa hipótese é relaxada nos testes IPS e CIPS. A vantagem do teste CIPS em relação aos demais é o tratamento explícito de dependência cross-section, problema típico de painéis de taxa de câmbio (e preço relativo). Este tratamento se dá pela inclusão de valores defasados das médias cross-section das sé-

8 A escolha do período inicial também esteve condicionada à necessidade dos dados setoriais deverem refletir exatamente o índice geral de preços. A inclusão de Goiânia acontece apenas em janeiro de 1991, o que fornece o maior período amostral possível com o conjunto completo de RMs pertencentes à amostra. 
ries em nível ou em primeira diferença, ampliando as regressões do tipo Dickey-Fuller Aumentado (ADF) padrão.

Tabela 1 -Testes de raiz unitária para painéis com preços relativos

\begin{tabular}{|c|c|c|c|c|c|c|}
\hline \multirow{2}{*}{ Numerário } & \multicolumn{3}{|c|}{ Setoriais } & \multicolumn{3}{|c|}{ Agregados } \\
\hline & LLC & IPS & CIPS & LLC & IPS & CIPS \\
\hline \multirow{2}{*}{ Brasil } & $-10,6306$ & $-14,8060$ & $-2,4180$ & $-3,1470$ & $-3,0756$ & $-2,1550$ \\
\hline & $(0,0000)$ & $(0,0000)$ & $(-2,0700)$ & $(0,0008)$ & $(0,0011)$ & $(-2,1000)$ \\
\hline \multirow{2}{*}{ Belém } & $-14,3533$ & $-13,4883$ & $-2,2540$ & $-1,9200$ & $-2,6370$ & $-2,4380$ \\
\hline & $(0,0000)$ & $(0,0000)$ & $(-2,0700)$ & $(0,0274)$ & $(0,0042)$ & $(-2,1000)$ \\
\hline \multirow{2}{*}{ Belo Horizonte } & $-15,0206$ & $-17,7797$ & $-2,3400$ & $-2,9408$ & $-2,9689$ & $-2,2980$ \\
\hline & $(0,0000)$ & $(0,0000)$ & $(-2,0700)$ & $(0,0016)$ & $(0,0015)$ & $(-2,1000)$ \\
\hline \multirow{2}{*}{ Brasília } & $-15,5223$ & $-19,0686$ & $-2,4480$ & $-2,9954$ & $-2,9976$ & $-2,6190$ \\
\hline & $(0,0000)$ & $(0,0000)$ & $(-2,0700)$ & $(0,0014)$ & $(0,0014)$ & $(-2,1000)$ \\
\hline \multirow{2}{*}{ Curitiba } & $-10,8315$ & $-13,9822$ & $-2,4240$ & $-3,0573$ & $-3,2472$ & $-2,1170$ \\
\hline & $(0,0000)$ & $(0,0000)$ & $(-2,0700)$ & $(0,0011)$ & $(0,0006)$ & $(-2,1000)$ \\
\hline \multirow{2}{*}{ Fortaleza } & $-9,3148$ & $-14,2341$ & $-2,745$ & $-2,1722$ & $-2,7834$ & $-2,4700$ \\
\hline & $(0,0000)$ & $(0,0000)$ & $(-2,0700)$ & $(0,0149)$ & $(0,0027)$ & $(-2,1000)$ \\
\hline \multirow{2}{*}{ Goiânia } & $-15,1203$ & $-18,0545$ & $-2,5580$ & $-2,9839$ & $-2,9783$ & $-2,1750$ \\
\hline & $(0,0000)$ & $(0,0000)$ & $(-2,0700)$ & $(0,0014)$ & $(0,0014)$ & $(-2,1000)$ \\
\hline \multirow{2}{*}{ Porto Alegre } & $-13,2429$ & $-19,0240$ & $-2,4970$ & $-2,9964$ & $-2,6942$ & $-2,1220$ \\
\hline & $(0,0000)$ & $(0,0000)$ & $(-2,0700)$ & $(0,0014)$ & $(0,0035)$ & $(-2,1000)$ \\
\hline \multirow{2}{*}{ Recife } & $-15,9820$ & $-18,6570$ & $-2,8100$ & $-2,1466$ & $-1,9777$ & $-2,0850^{*}$ \\
\hline & $(0,0000)$ & $(0,0000)$ & $(-2,0700)$ & $(0,0159)$ & $(0,0240)$ & $(-2,1000)$ \\
\hline \multirow{2}{*}{ Rio de Janeiro } & $-10,5337$ & $-13,5731$ & $-2,5790$ & $-2,4812$ & $-2,6374$ & $-2,3370$ \\
\hline & $(0,0000)$ & $(0,0000)$ & $(-2,0700)$ & $(0,0065)$ & $(0,0042)$ & $(-2,1000)$ \\
\hline \multirow{2}{*}{ Salvador } & $-11,8032$ & $-15,1207$ & $-3,0430$ & $-3,0684$ & $-2,8564$ & $-2,3090$ \\
\hline & $(0,0000)$ & $(0,0000)$ & $(-2,0700)$ & $(0,0011)$ & $(0,0021)$ & $(-2,1000)$ \\
\hline \multirow{2}{*}{ São Paulo } & $-10,5650$ & $-13,2408$ & $-2,8140$ & $-4,0599$ & $-3,6144$ & $-2,4420$ \\
\hline & $(0,0000)$ & $(0,0000)$ & $(-2,0700)$ & $(0,0000)$ & $(0,0002)$ & $(-2,1000)$ \\
\hline
\end{tabular}

Nota: p-valor entre parênteses, com exceção do teste CIPS, que não possui distribuição padrão e, portanto, reportam-se os valores críticos tabelados para $N, T=(100,200)$ para os painéis de preços relativos setoriais, e $N, T=(10,200)$ para aqueles painéis com preços relativos agregados, ao nível de $5 \%$ de significância. ${ }^{*}$ Não se rejeita $H_{0}$. Para os painéis com preços relativos setoriais, o número de lags necessários para que o resíduo seja ruído branco foram definidos, para os testes LLC e IPS, de forma ótima utilizando-se como critério de informação a estatística de Schwarz, permitindo-se no máximo 12 lags. Já para os painéis com preços relativos agregados, o número de lags necessários para que o resíduo seja ruído branco foram definidos, para os testes LLC e IPS, de forma ótima utilizando-se como critério de informação a estatística de Schwarz, permitindo-se no máximo 12 (LLC) e 8 lags para o IPS. Para o teste CIPS, o número de lags foi definido utilizando-se um teste de Wald partindo-se da ausência de lags para o limite máximo de 12 lags. 
A Tabela 1 reporta os resultados dos testes de raiz unitária para ambos os tipos de painel. Para os painéis com preços relativos setoriais, não há qualquer evidência de presença de raiz unitária, visto que a hipótese nula é rejeitada em todos os testes. Já para os painéis de preços relativos agregados, o teste CIPS aponta a presença de raiz unitária apenas quando Recife é usado como numerário. De modo geral, os resultados são, portanto, consistentes com estacionaridade em ambos os tipos de painel.

\section{Meia-vida e a Ordem do Processo Autorregressivo - $A R(p)$}

Os painéis de preços relativos setoriais utilizados neste trabalho seguem um processo autorregressivo de ordem $p$ com efeito fixo e heterogeneidade nos coeficientes autorregressivos das unidades individuais, que podem ser descritos por:

$$
q_{i c t}=\alpha_{i c}+\sum_{j=1}^{p} \rho_{i c j} q_{i c t-j}+e_{i c t}
$$

em que $q_{i c t}$ é definido como em (1). De forma análoga a (3.a), para a equação que descreve o processo autorregressivo dos painéis de preços relativos agregados, suprime-se o subscrito $i$ e tem-se $q_{c t}$ como definido pela Equação (2), ${ }^{9}$ ou seja:

$$
q_{c t}=\alpha_{c}+\sum_{j=1}^{p} \rho_{j} q_{c t-j}+e_{c t}
$$

$\mathrm{Na} e q(3 . a)$, controla-se para dois possíveis efeitos fixos $\left(\alpha_{i c}\right)$, o da RM e o do setor, de modo que um mesmo setor em RMs distintas é tratado como uma unidade individual diferente. Adicionalmente, os coeficientes autorregressivos $\left(\rho_{i c j}\right)$ também podem variar entre RMs e setores. Esta abordagem difere da adotada em IMRR (2005a), uma vez que, em sua especificação, permite-se que o intercepto varie apenas entre países, en-

9 Deve-se suprimir também todos os subscritos dos parâmetros autorregressivos, uma vez que as estimações para este tipo de painel não levam em conta a heterogeneidade entre as RMs e são realizadas apenas para confirmar que estes dados reportam, quando estimados sem tratamento adequado, meia-vida dentro do intervalo-consenso. 
quanto os coeficientes autorregressivos são heterogêneos apenas entre os setores.

É necessário definir a ordem do processo autorregressivo para os painéis considerando o Brasil e cada uma das RMs como numerário. A especificação correta do modelo a ser estimado é especialmente importante nesse tipo de problema, pois a definição incorreta da ordem do processo autorregressivo gera distorções no cálculo da meia-vida.

A seleção da ordem do processo autorregressivo em painéis pelo critério de informação de Schwarz (BIC) é inconsistente na presença de parâmetros incidentais e superestima a ordem do processo autorregressivo com considerável probabilidade, mesmo sem efeito fixo no painel dinâmico. Para resolver este problema, Han, Phillips e Sul (2017) propõem o uso de alguns critérios de informação modificados que são consistentes em painéis dinâmicos, comportando-se bem para diferentes tamanhos de $N$ e $T$.

Tabela 2 - Definição da ordem dos processos autorregressivos

\begin{tabular}{lccccc}
\hline & \multicolumn{2}{c}{ Preço Relativo Desagregado } & & \multicolumn{2}{c}{ Preço Relativo Agregado } \\
\cline { 2 - 3 } \cline { 5 - 6 } Numerário & $K_{0}$ & $K_{2}$ & & $K_{0}$ & $K_{2}$ \\
\hline Brasil & 12 & 4 & & 12 & 3 \\
Belém & 12 & 5 & & 12 & 6 \\
Belo Horizonte & 12 & 3 & & 12 & 1 \\
Brasília & 12 & 3 & & 12 & 2 \\
Curitiba & 12 & 11 & & 12 & 3 \\
Fortaleza & 12 & 11 & & 12 & 12 \\
Goiânia & 12 & 3 & & 12 & 1 \\
Porto Alegre & 12 & 12 & & 12 & 12 \\
Recife & 12 & 5 & & 12 & 5 \\
Rio de Janeiro & 12 & 4 & & 12 & 1 \\
Salvador & 12 & 4 & & 12 & 12 \\
\hline São Paulo & 12 & 4 & 12 & 12 \\
\hline
\end{tabular}

Nota: A ordem máxima permitida para o processo autorregressivo foi $p_{m a ́ x}=12$.

Os resultados para ambos os painéis e cada um dos numerários estão na Tabela 2. Dos 2 critérios de informação reportados - o BIC tradicional e enviesado $\left(K_{0}\right)$ e o BIC modificado $\left(K_{2}\right)$-, optou-se por utilizar a ordem de 
defasagens apontada como adequada pelo BIC modificado, satisfazendo, portanto, o critério da parcimônia, uma vez que este critério recomendou a utilização de menos lag's na maioria dos casos.

Dada a ordem $p$ de cada um dos processos autorregressivos, as meias-vidas de convergência dos preços relativos - agregados e desagregados por grupos - são aproximadas pela fórmula:

$$
M V(\beta)=\frac{\ln (0,5)}{\ln (1+\beta)}
$$

independentemente da existência de meia-vida bem definida. Em que $\beta$ é a "velocidade de convergência" da representação de correção de erro do processo $A R(p)$ dada por:

$$
\Delta q_{i c t}=\beta q_{i c t-1}+\sum_{j=1}^{p-1} \rho_{i c j}^{*} q_{i c t-j}+e_{i c t}
$$

onde $\rho_{i c j}^{*}=-\sum_{k=j+1}^{p} \rho_{i c k}$ e $\beta=\sum_{j=1}^{p} \rho_{i c j}-1$. Portanto, (4) pode ser reescrita da seguinte forma para as regressões estimadas:

$$
M V\left(\sum_{j=1}^{p} \widehat{\rho_{J}}\right)=\frac{\ln (0,5)}{\ln \left(\sum_{j=1}^{p} \widehat{\rho_{J}}\right)}
$$

Seong, Morshed e Ahn (2006) mostram que existem problemas com esta medida de meia-vida, principalmente na presença de raiz unitária. Este problema, entretanto, terá tratamento adequado mais tarde, na seção 6 .

\section{A Questão da Heterogeneidade}

O viés de agregação dinâmico é apontado por IMRR (2005a) como fator explicativo do enigma da PPC. Eles revelam que a taxa de câmbio real agregada é persistente porque os setores que a compõem têm dinâmica heterogênea - sendo os métodos convencionais de estimação em séries de tempo e painéis incapazes de controlá-la. Neste sentido, o viés de agre- 
gação surgiria por conta da suposição implícita de que todos os preços relativos que compõem a taxa de câmbio real convergem para a paridade à mesma velocidade.

Do ponto de vista teórico, os autores mostram que a falha no tratamento da heterogeneidade na dinâmica dos preços relativos dá origem a um viés positivo que cresce com o grau de heterogeneidade. Ao agregar os setores de um painel de preços relativos de bens para um único par de países ${ }^{10} \mathrm{e}$ assumindo, sem perda de generalidade, que estes $N$ setores seguem um processo autorregressivo de primeira ordem, o viés de agregação é descrito pela equação abaixo:

$$
\Delta=\sum_{i=1}^{N}\left(\rho_{i}-\rho\right) \delta_{i}
$$

em que

$$
\delta_{i}=\left[\frac{\omega_{i}^{2} \sigma_{i}^{2}}{1-\rho_{i}^{2}}+\sum_{i \neq j}^{N} \frac{\omega_{i} \omega_{j} \sigma_{i j}}{1-\rho_{i} \rho_{j}}\right] /\left[\sum_{i=1}^{N}\left(\frac{\omega_{i}^{2}}{1-\rho_{i}^{2}} \sigma_{i}^{2}+\sum_{i \neq j}^{N} \frac{\omega_{i} \omega_{j} \sigma_{i j}}{1-\rho_{i} \rho_{j}}\right)\right]
$$

e $\rho$ é o valor do parâmetro autorregressivo comum entre os setores; ${ }^{11}$ $\omega_{i}$ e $\omega_{j}$ são os pesos dos $i$-ésimo e $j$-ésimo setores na construção do preço relativo agregado, respectivamente; $\rho_{i}$ e $\rho_{j}$ são os coeficientes dos processos $A R(1)$ dos $i$-ésimo e $j$-ésimo setores, respectivamente; $\sigma_{i}^{2}$, é a variância do termo de erro do $i$-ésimo setor; e, $\sigma_{i j}$, é a covariância entre os $i$-ésimo e $j$-ésimo setores. IMRR (2005a) provam que o viés é positivo desde que os coeficientes $\delta_{i}$ sejam positivamente correlacionados com os parâmetros de persistência $\rho_{i}$.

Quando a heterogeneidade é levada em conta, a persistência da taxa de câmbio se reduz bastante. ${ }^{12}$ A meia-vida estimada em IMRR (2005a) é, portanto, de aproximadamente 11 meses, resultado consistente com os de

\footnotetext{
${ }^{10}$ Os autores generalizam o resultado para o painel da taxa de câmbio real.

${ }^{11}$ Em painéis com coeficiente angular heterogêneo, tem-se que $\rho_{i}=\rho+\eta_{i}^{\rho}$ IMRR (2005a) assumem que $\eta_{i}^{\rho}$ tem média zero e variância constante. E que o conjunto dos coeficientes aleatórios $\rho_{i}$ tem suporte dentro do intervalo ]-1,1[.

12 A meia-vida cai ao valor compatível com o previsto em modelos de equilíbrio geral computáveis, na vizinhança de um ano.
} 
modelos de equilíbrio geral dinâmico estocástico com rigidez nominal e bem a abaixo do intervalo-consenso proposto por Rogoff (1996).

Chen e Engel (2005) - CE (2005), daqui em diante - contestam os resultados de IMRR (2005a). As críticas concentram-se nos seguintes pontos: aplicabilidade do viés de agregação para o enigma da PPC, visto que o viés não é necessariamente positivo (há situações em que $\Delta<0$ ); o tamanho do viés seria muito menor do que aquele que as simulações reportam; erros de medida, que provocam menores estimativas de persistência baseadas sobre dados setoriais, contaminam os resultados enquanto dados agregados seriam imunes a este problema; e o viés de pequena amostra, que seria a principal razão deste erro.

Em resposta, IMRR (2005b) argumentam, primeiramente, que a expansão de Taylor realizada para linearizar o viés de agregação em CE (2005) é feita em torno do caso homogêneo e, como já salientado, a magnitude do viés cresce com a heterogeneidade. Adicionalmente, os autores destacam que, independentemente do ponto escolhido para a aproximação, o mais importante é se as restrições impostas são plausíveis empiricamente, o que não é o caso em CE (2005). Por fim, os autores mostram que a correlação positiva entre $\delta_{i}$ e $\rho_{i}$, pré-condição para que o viés de agregação $\Delta$ seja positivo, está presente em IMRR (2005a) e em CE (2005).

Sobre o tamanho do viés, IMRR (2005b) respondem que as simulações em CE (2005) não produzem um grande viés de agregação porque a extensão da heterogeneidade usada em sua simulação é menor que aquela presente em seus dados e, além disso, as condições iniciais escolhidas atuam para minimizar o viés.

Quanto à questão do erro de medida, o contra-argumento diz que, para esta questão ser convincente, seria necessário observar estimativas de persistência substancialmente menores em nível setorial em relação a estimações baseadas sobre dados agregados, o que não acontece. IMRR (2005b) também apontam que nas estimações em CE (2005) um estimador inadequado foi utilizado. Quando um estimador que leva em conta a heterogeneidade é utilizado, a meia-vida cai substancialmente.

No que se refere ao viés de pequena amostra do estimador de mínimos quadrados, os autores apontam problemas no procedimento para a correção do viés usado em CE (2005), dado que se conhece muito pouco 
sobre as propriedades dos métodos utilizados ${ }^{13}$ quando aplicados a painéis heterogêneos com efeitos comuns correlacionados, visto como o principal problema.

Como uma alternativa aos modelos com fricções nominais que não conseguem reproduzir a alta persistência encontrada nas pesquisas empíricas, Carvalho e Nechio (2011) desenvolvem um modelo multissetorial com dois países e rigidez de preços. Em seu modelo, a extensão da rigidez de preços, distinta em cada setor, determina a heterogeneidade na dinâmica da taxa de câmbio real setorial. Os autores mostram que, em resposta a um choque nominal, a taxa de câmbio real agregada é muito mais volátil e persistente no modelo multissetorial com heterogeneidade do que em um modelo de uma economia contrafactual sem heterogeneidade. Esse resultado reforça a ideia do viés de agregação como solução para o enigma da PPC.

Adicionalmente, Carvalho e Nechio (2011) decompõem, a partir de seu modelo estrutural, os efeitos da heterogeneidade em dois: o aggregation effect e o counterfactuality effect. Essa decomposição é utilizada para reconciliar os resultados aparentemente conflitantes de IMRR (2005a) e CE (2005). O resultado conflitante, segundo os mesmos, surge devido a IMRR (2005a) medirem a soma dos efeitos decompostos enquanto CE (2005) medem em seu exercício apenas o aggregation effect, que é de fato pequeno. Utilizando método de regressão quantílica para a taxa de câmbio real de 15 países pertencentes à União Europeia, Mayoral e Gadea (2011) obtêm resultados que reforçam o achado de Carvalho e Nechio (2011).

Para verificar a presença de heterogeneidade, utiliza-se o teste de homogeneidade proposto por Pesaran e Yamagata (2008), que tem como nula a hipótese que os coeficientes autorregressivos são idênticos entre as unidades individuais, isto é, tem $H_{0}$ de homogeneidade. A equação do teste, adequado para a dimensão dos dados, uma vez que se tem $T \geq N$, foi especificada de acordo com a ordem $p$ do processo autorregressivo reportada na Tabela 2. Uma vez que, com exceção dos painéis agregados que têm como numerário Belo Horizonte, Goiânia e São Paulo, rejeitam-se a nula em todos os demais casos, pode-se dizer que em ambos os painéis há a tendência de rejeitar a hipótese nula ao nível de 5\% de significância. Os resultados para os painéis de preço relativo desagregado corroboram aquele obtido em IMRR (2005a). Já para os painéis de preço relativo agregado, o

${ }^{13}$ Para a correção do viés de amostra pequena, CE (2005) usam os procedimentos padrão sugeridos por So e Shin (1999) e Kilian (1998). 
resultado tende a diferir do achado de IMRR (2005a) e difere também do obtido em Bastos, Ferreira e Arruda (2018), que utilizam o mesmo teste para dados de preços relativos agregados de cidades brasileiras em um painel $A R(1)$ com frequência anual e não rejeitam a nula de homogeneidade. Tem-se aqui, portanto, com a rejeição da hipótese de homogeneidade dos coeficientes autorregressivos das unidades individuais, um resultado que reforça a heterogeneidade - entre cidades e setores - como um problema relevante em estudos da PPC.

Tabela 3 - Teste de homogeneidade de Pesaran e Yamagata

\begin{tabular}{lcc}
\hline \multirow{2}{*}{ Numerário } & \multicolumn{2}{c}{ Preço Relativo } \\
\cline { 2 - 3 } Brasil & Agregado & Desagregado \\
\cline { 2 - 3 } Belém & 18,9440 & 46,2130 \\
& $(0,0000)$ & $(0,0000)$ \\
Belo Horizonte & 5,9360 & 45,4930 \\
& $(0,0000)$ & $(0,0000)$ \\
Brasília & $0,0630^{*}$ & 38,2210 \\
& $(0,9498)$ & $(0,0000)$ \\
Curitiba & 6,5600 & 35,3210 \\
Fortaleza & $(0,0000)$ & $(0,0000)$ \\
& 2,0950 & 45,7080 \\
Goiânia & $(0,0362)$ & $(0,0000)$ \\
& 3,2730 & 52,7020 \\
Porto Alegre & $(0,0011)$ & $(0,0000)$ \\
& $1,3500^{*}$ & 34,8720 \\
Recife & $(0,1770)$ & $(0,0000)$ \\
& 4,5410 & 74,6610 \\
Rio de Janeiro Paulo & $(0,0000)$ & $(0,0000)$ \\
& 8,3140 & 47,4570 \\
& $(0,0000)$ & $(0,0000)$ \\
& 3,8340 & 37,6920 \\
& $(0,0001)$ & $(0,0000)$ \\
& 4,5930 & 34,7330 \\
& $(0,0000)$ & $(0,0000)$ \\
& $-1,6090^{*}$ & 46,4630 \\
& $(0,1076)$ & $(0,0000)$ \\
\hline
\end{tabular}

Nota: Estatística $\widetilde{\Omega}$ Ajustado. Valor-p entre parênteses. ${ }^{*}$ Não se rejeita $H_{0}$. 
Em outra linha, Gadea e Mayoral (2009) argumentam que o resultado obtido em IMRR (2005a) é fruto de um procedimento incorreto de estimação da meia-vida a partir da função impulso-resposta. Logo, o viés oriundo da agregação de setores com dinâmica de convergência distinta não seria solução para o enigma da PPC e o puzzle permaneceria sem solução. Os detalhes desta crítica, bem como o procedimento sugerido como correto para a estimação da meia-vida, serão apresentados mais a diante.

\section{Resultados}

Seguindo IMRR (2005a), antes da estimação dos painéis de preços relativos setoriais - que são componentes do preço relativo agregado -, realiza-se a estimação em painel com os dados agregados utilizando-se dois estimadores: (i) o de efeito fixo com correção baseada em um bootstrap iterativo para o viés de pequena amostra e que permite a estimação de processos autorregressivos de ordem mais alta; ${ }^{14}$ e (ii) o estimador system-gmm proposto por Arellano e Bover (1995) e Blundell e Bond (1998), que permite o uso de instrumentos internos para corrigir o viés do painel dinâmico. É necessário destacar que o estimador system-gmm pertence a um conjunto de estimadores adequados para painéis conhecidos como short panels, painéis em que a dimensão cross-section dos dados é maior do que a dimensão temporal dos mesmos, o que não é o caso dos dados usados neste estudo. ${ }^{15}$ Embora inadequado para long panels, este estimador foi, durante um bom tempo, amplamente utilizado para esta estrutura de dados, pois são relativamente recentes os desenvolvimentos que permitem que a dimensão temporal de dados em painel seja explorada de forma mais adequada.

\footnotetext{
${ }^{14}$ Este estimador, proposto por Everaert e Pozzi (2007), permite dependência cross-section contemporânea.

15 Os painéis de preços relativos agregados têm dimensão $N=10$ e $T=276$, enquanto para os painéis de preços relativos desagregados têm-se $N=90$ e $T=276$. As exceções são os painéis de preços relativos agregado e desagregado que têm o Brasil como numerário, para os quais $N=11$ e $N=99$, respectivamente.
} 
Tabela 4 - Meias-vidas para painéis de preços relativos agregados

\begin{tabular}{|c|c|c|c|c|}
\hline \multirow[b]{2}{*}{ Numerário } & \multicolumn{2}{|c|}{ FE c/ correção Bootstrap } & \multicolumn{2}{|c|}{ System-GMM ${ }^{\mathrm{a}}$} \\
\hline & $\sum_{j=1}^{p} \widehat{\rho}_{J}$ & $\left(\sum_{j=1}^{p} \hat{\rho}\right.$ & $\sum_{j=1}^{p} \widehat{\rho}_{J}$ & $\left(\sum_{j=1}^{p} \hat{\rho}\right.$ \\
\hline Brasil & 0,9836 & 42,04 & 0,9908 & 75,03 \\
\hline Belém & 0,9813 & 36,71 & 0,9885 & 60,18 \\
\hline Belo Horizonte & 0,9928 & 96,42 & 0,9863 & 50,37 \\
\hline Brasília & 0,9712 & 23,69 & 0,9830 & 40,35 \\
\hline Curitiba & 0,9794 & 33,27 & 0,9908 & 75,32 \\
\hline Fortaleza & 0,9923 & 89,90 & 0,9869 & 52,73 \\
\hline Goiânia & 0,9704 & 23,06 & 0,9813 & 36,74 \\
\hline Porto Alegre & 0,9782 & 31,41 & 0,9900 & 68,70 \\
\hline Recife & 0,9550 & 15,05 & 0,9781 & 31,31 \\
\hline Rio de Janeiro & 0,9850 & 45,93 & 0,9880 & 57,27 \\
\hline Salvador & 0,9785 & 31,88 & 0,9867 & 51,86 \\
\hline São Paulo & 1,0018 & $\infty^{\mathrm{b}}$ & 0,9930 & 98,42 \\
\hline Mediana & 0,9803 & 33,27 & 0,9875 & 55,00 \\
\hline Mínimo & 0,9550 & 15,05 & 0,9781 & 31,31 \\
\hline Máximo & 0,9928 & 96,42 & 0,9930 & 98,42 \\
\hline
\end{tabular}

Nota: ${ }^{a}$ o resultado destas estimações devem ser vistos com cautela, uma vez que, para alguns numerários, os coeficientes da variável dependente defasada não estão dentro do intervalo das estimações pooled e within-groups e, além disso, os testes de autocorrelação e de validade dos instrumentos também não são satisfeitos; bainel tendo São Paulo como referência apresentou comportamento explosivo.

A Tabela 4 traz a meia-vida dos desvios da PPC para os numerários e métodos considerados. Como esperado, os resultados concentram-se próximo do intervalo-consenso, com uma meia-vida mediana aproximada de 33,27 meses. Estes resultados estão em linha com aqueles obtidos em Bastos, Ferreira e Arruda (2018), que também não conferem tratamento adequado ao viés de agregação dinâmica.

Para averiguar se o viés de agregação de setores com dinâmica heterogênea se confirma para as RMs brasileiras, é necessário realizar estimação para o painel de preços relativos desagregados. Neste trabalho, permite-se heterogeneidade no coeficiente autorregressivo entre setores e RMs, além de interceptos com efeito fixo também variando entre estas unidades econô- 
micas. Esta abordagem é distinta da utilizada em IMRR (2005a), na qual apenas os interceptos são distintos entre países, enquanto os coeficientes autorregressivos variam entre setores, assumindo-se que a dinâmica dos setores é idêntica entre as unidades econômicas. Aqui, portanto, segue-se o tratamento sugerido em Gadea e Mayoral (2009).

Para tanto, utiliza-se a estimação proposta em Chudik e Pesaran (2015), a qual estende o estimador de Pesaran (2006) que usa a abordagem de Efeitos Comuns Correlacionados (CCE) para modelos com estrutura de erro multifatorial. Os autores mostram que o estimador CCE mean group (CCEMG) será válido mesmo na presença de dependência cross-section desde que as seguintes condições sejam satisfeitas: um número suficientemente grande de defasagens das médias cross-sections devem ser incluídas nas equações individuais do painel; e o número de médias cross-sections deve ser pelo menos tão grande quanto o número de fatores comuns não observados. Assim, a versão aumentada de (3) é dada por

$$
q_{i c t}=\alpha_{i c}+\sum_{j=1}^{p} \rho_{i c j} q_{i c t-j}+\sum_{l=0}^{p_{T}} \delta_{i c l} \bar{q}_{t-l}+e_{i c t}
$$

para $i=1,2, \ldots, N_{1}$ e $c=1,2, \ldots, N_{2}$, onde $\bar{p}_{t}=N^{-1} \sum_{i=1}^{N} p_{i c t} \therefore N=N_{1} \times N_{2}$ em que, neste trabalho, $N_{1}$ refere-se ao número de setores enquanto $N_{2}$ é o número de RMs. $p_{T}$ é a parte inteira de $T^{1 / 3}$, denotado por $p_{T}=\left[T^{1 / 3}\right]$. Aqui, adota-se $p_{T}=7$ para $T=276$. Os estimadores CCEMG dinâmicos de $\alpha$ e $\rho_{j}$ são obtidos pela média aritmética dos estimadores de mínimos quadrados de $\alpha_{i c}$ e $\rho_{i c j}$ baseados em (8).

Adicionalmente, utilizam-se 2 métodos de correção para o viés de amostra pequena: o método conhecido como half-panel jackknife e o método de ajustamento recursivo pela média (recursive mean adjustment - RMA). Os autores destacam ainda que ambas as correções do viés podem ser consideradas efetivas na redução do viés de pequena amostra do estimador, entretanto, o método jackknife acaba por ser mais eficaz em lidar com o viés, sendo aparentemente útil apenas para os coeficientes dos lags da variável dependente. ${ }^{16}$

${ }^{16} \mathrm{O}$ método de correção half-panel jackknife, usado para ajudar a eliminar o viés, é suficiente para lidar com distorções de tamanho apenas se $T$ é suficientemente grande, o que parece ser o caso deste trabalho, uma vez que a dimensão temporal do painel de preço relativo heterogêneo é de $T=276$, maior do que $T=200$ usado nas simulações de Chudik e Pesaran (2015). 
Portanto, este trabalho concentra-se nos resultados corrigidos pelo método jackknife. O estimador CCEMG com correção de viés pelo método jackknife é dado por:

$$
\tilde{\pi}_{M G}=2 \hat{\pi}_{M G}-\frac{1}{2}\left(\hat{\pi}_{M G}^{a}+\hat{\pi}_{M G}^{b}\right)
$$

onde $\pi_{i c}=\left(\rho_{i c 1}, \ldots, \rho_{i c p}\right)$ e $\hat{\pi}_{M G}=N^{-1} \sum_{h=1}^{N} \pi_{h} \therefore N=N_{1} \times N_{2}$, em que $h$ denota a junção entre o setor $i$ e sua respectiva RM $c$, constituindo uma única unidade individual. $\hat{\pi}_{M G}^{a}$ refere-se ao estimador CCEMG obtido a partir da primeira metade do período de tempo disponível, isto é, para $t=1,2, \ldots,[T / 2]$, e $\hat{\pi}_{M G}^{b}$ é o estimador CCEMG obtido usando a segunda metade do período amostral $t=[T / 2]+1,[T / 2]+2, \ldots, T$.

A fim de verificar o sucesso da estimação em mitigar a dependência cross-section, realiza-se um teste de fraca dependência cross-section proposto por Pesaran (2015), o teste CD. Este teste tem nula de que o termo de erro possui fraca dependência cross-section. Com exceção do painel que tem Salvador como numerário, todas as estatísticas CD rejeitam a hipótese nula ao nível de $5 \%$ de significância. ${ }^{17}$

A Tabela 5 traz os resultados das estimações, bem como as meias-vidas aproximadas. As meias-vidas reportadas a partir do estimador CCEMG dinâmico corrigido pelo método RMA são substancialmente inferiores àquelas geradas pelo estimador corrigido pelo método jackknife. Entretanto, como mencionado anteriormente, o último é mais efetivo que o primeiro em mitigar o viés de pequena amostra. O resultado está em linha com o obtido em IMRR (2005a), com uma meia-vida mediana de aproximadamente 12 meses, oscilando entre 7,93 - 16,59 meses.

17 Estatística CD foi construída a partir dos resíduos das estimações CCEMG corrigidas pelo método half-panel jackknife. Mesmo com a inclusão das médias cross-section, a rejeição da nula neste teste sugere que ainda pode haver dependência. 
Tabela 5 - Meias-vidas para painéis de preços relativos desagregados

\begin{tabular}{|c|c|c|c|c|c|}
\hline \multirow[b]{2}{*}{ Numerário } & \multicolumn{2}{|c|}{ Jackknife Bias Correction } & \multicolumn{2}{|c|}{ Recursive Mean Adjustment } & \multirow{2}{*}{$\begin{array}{c}\text { Estatística } \\
\text { CD }\end{array}$} \\
\hline & $\sum_{j=1}^{p} \widehat{\rho}_{J}$ & $\left(\sum_{j=1}^{p} \widehat{\rho_{J}}\right)$ & $\sum_{j=1}^{p} \widehat{\rho}_{J}$ & $\left(\sum_{j=1}^{p} \widehat{\rho}_{J}\right)$ & \\
\hline Brasil & 0,9591 & 16,59 & 0,7837 & 2,84 & $\begin{array}{c}-9,73 \\
(0,0000)\end{array}$ \\
\hline Belém & 0,9574 & 15,91 & 0,8664 & 4,84 & $\begin{array}{c}-3,87 \\
(0,0001)\end{array}$ \\
\hline Belo Horizonte & 0,9351 & 10,34 & 0,8123 & 3,33 & $\begin{array}{c}-6,08 \\
(0,0000)\end{array}$ \\
\hline Brasília & 0,9484 & 13,09 & 0,8341 & 3,82 & $\begin{array}{c}-8,65 \\
(0,0000)\end{array}$ \\
\hline Curitiba & 0,9566 & 15,61 & 0,7470 & 2,38 & $\begin{array}{c}-3,36 \\
(0,0008)\end{array}$ \\
\hline Fortaleza & 0,9401 & 11,22 & 0,7816 & 2,81 & $\begin{array}{c}-2,49 \\
(0,0127)\end{array}$ \\
\hline Goiânia & 0,9447 & 12,17 & 0,7994 & 3,10 & $\begin{array}{c}-6,90 \\
(0,0000)\end{array}$ \\
\hline Porto Alegre & 0,9496 & 13,39 & 0,7726 & 2,69 & $\begin{array}{c}2,23 \\
(0,0256)\end{array}$ \\
\hline Recife & 0,9163 & 7,93 & 0,7657 & 2,60 & $\begin{array}{c}-4,22 \\
(0,0000)\end{array}$ \\
\hline Rio de Janeiro & 0,9470 & 12,73 & 0,8037 & 3,17 & $\begin{array}{c}-6,40 \\
(0,0000)\end{array}$ \\
\hline Salvador & 0,9364 & 10,56 & 0,8051 & 3,20 & $\begin{array}{c}0,34 \\
(0,7314)\end{array}$ \\
\hline São Paulo & 0,9289 & 9,39 & 0,8133 & 3,35 & $\begin{array}{c}-6,13 \\
(0,0000)\end{array}$ \\
\hline Mediana & 0,9458 & 12,45 & 0,8016 & 3,13 & \\
\hline Mínimo & 0,9163 & 7,93 & 0,7470 & 2,38 & \\
\hline Máximo & 0,9591 & 16,59 & 0,8664 & 4,84 & \\
\hline
\end{tabular}

Nota: valores-p entre parênteses. 


\section{A Acurácia da Meia-Vida em Processos $A R(p)$}

$\mathrm{Na}$ literatura econômica, a medida de meia-vida tem sido utilizada para calcular a persistência dos desvios das variáveis econômicas de suas tendências de longo prazo. Em estudos de preços relativos, Seong, Morshed e Ahn (2006) destacam a importância desta medida para auxiliar policy makers no desenho de políticas monetárias capazes de lidar com o impacto e persistência da divergência regional da taxa de inflação.

Estes autores mostram a imprecisão/sensibilidade da medida de meia-vida aproximada em processos autorregressivos de ordem mais alta - e mesmo em processos $A R(1)$-, sobretudo em processos não estacionários, visto que a meia-vida diverge para o infinito sempre que o coeficiente autorregressivo converge para um. Para um modelo $A R(1)$, por exemplo, Seong, Morshed e Ahn (2006) estimam que obter uma meia-vida de 3,6 anos ou menos é tão provável quanto obter uma meia-vida de 9,6 anos ou mais, evidenciando a sensibilidade desta medida aproximada a erros amostrais.

Recomenda-se, portanto, o cálculo da medida de meia-vida exata obtida diretamente a partir da IRF de cada um de seus respectivos modelos. Para obtê-la, pode-se derivar a fórmula exata da meia-vida, satisfazendo $\psi_{M V}=0,5$ para cada um dos processos autorregressivos em estudo, em que $M V$ corresponde ao período $j$ em que o valor da função impulso-resposta, $\psi_{j}$ é igual a um meio.

$\mathrm{Ou}$, alternativamente, pode-se proceder como sugerem Kilian e Zha (2002). Seja $\psi_{j}$, para $j=0,1, \ldots, 40 f,{ }^{18}$ a resposta ao impulso de $p_{t+j}$ para uma mudança de uma unidade em $e_{t}$ no período $t .{ }^{19}$ Dentro do intervalo de tempo estipulado, encontra-se o maior instante $h$ que satisfaça $\left|\psi_{h-1}\right| \geq 0,5$ e $\left|\psi_{h}\right|<0,5$. Se esta condição é satisfeita e, adicionalmente, $\left|\psi_{j+k}\right|<0,5$ para todo $k>0$ dentro do intervalo $j=0,1, \ldots, 40 f$, diz-se que a meia-vida é atingida em $j=h$. Caso estas condições não sejam satisfeitas, situação em que a $I R F$ não decresce monotonicamente, diz-se que a meia-vida não é atingida dentro do intervalo que vai de 0 a $40 f$. A segunda coluna da Tabela 6 reporta as meias-vidas calculadas desta forma. Não se observa, entretanto, mudanças significantes, visto que, com exceção da estimação que tem Curitiba como numerário, as diferenças entre as

$18 f$ refere-se a frequência temporal dos dados. Se os dados são mensais, por exemplo, $f=12$.

19 Ignora-se, sem perda de generalidade, a dimensão cross-section da variável. 
meias-vidas em suas versões aproximada e exata foram sempre menores que 2 meses.

Além dos problemas já mencionados, Gadea e Mayoral (2009) apontam problemas no cálculo da meia-vida a partir IRF "média" como reportado aqui nos moldes de IMRR (2005a). O argumento concentra-se na afirmação de que, em vez de computar as IRFs individuais e, então, agregá-las pela média para produzir uma estimativa da $I R F$ setorial média, estima-se o valor médio dos coeficientes do modelo heterogêneo e, daí, utilizam-se estes valores para obter a IRF "média", como se o modelo fosse de coeficientes homogêneos, dado pelo valor médio dos coeficientes autorregressivos heterogêneos.

Entretanto, devido a $I R F$ ser uma função extremamente não linear, agregá-las pode produzir um resultado muito distinto daquele obtido ao agregar os coeficientes autorregressivos para depois calcular a IRF. E, ao proceder da segunda forma - como em IMRR (2005a) -, subestima-se o verdadeiro valor da meia-vida. Este fato é, segundo as mesmas, assegurado pela desigualdade de Jensen ${ }^{20}$ para a maioria dos casos empiricamente relevantes.

Para verificar se os dados reportados aqui reproduzem os resultados de Gadea e Mayoral (2009), isto é, meias-vidas substancialmente maiores, calcula-se a meia-vida conforme sugerido pelas mesmas, obtendo-se a IRF setorial média. Adicionalmente, agregam-se as $I R F$ s individuais pela mediana. Os resultados estão nas terceira e quarta colunas da Tabela 6, respectivamente. Para as agregações a partir da média, as $I R F s$ não decrescem monotonicamente dentro do intervalo considerado, por isso admite-se, seguindo as recomendações de Kilian e Zha (2002), que as meia-vidas são maiores do que 480 meses. ${ }^{21}$ Por outro lado, para o processo agregado pela mediana, medida de tendência central não sensível a valores extremos, obtêm-se meias-vidas levemente maiores, com meia-vida mediana da ordem de 13,5 meses. Tendo os resultados obtidos pelo método sugerido por Gadea e Mayoral (2009) como referência, não se pode afirmar que as meias-vidas retornam para o intervalo-consenso de 3 a 5 anos.

${ }^{20}$ A desigualdade de Jensen assegura que, para determinadas funções, o valor esperado de $f(X)$ é maior ou igual a função do valor esperado, $f(E(X))$. Portanto, se $X$ é uma variável aleatória que tem média finita, então, por exemplo, $E\left(X^{2}\right) \geq[E(X)]^{2}$, podendo $E\left(X^{2}\right)$ ser infinito.

${ }^{21}$ Kilian e Zha (2002) sugerem que, para IRFs que não satisfaçam as condições necessárias para o cômputo da meia-vida, assuma-se uma meia-vida de $40 f$, 480 meses para séries de frequência mensal, visto que meias-vidas maiores que $40 f$ podem ser consideradas sem diferenças significantes do ponto de vista econômico.. 
Tabela 6 - Meias-vidas exatas a partir das funções impulso-resposta

\begin{tabular}{|c|c|c|c|}
\hline \multirow{2}{*}{ Numerário } & \multirow{2}{*}{ à la IMRR } & \multicolumn{2}{|c|}{ à la Gadea e Mayoral } \\
\hline & & média & mediana \\
\hline Brasil & 15 & $>480$ & 16 \\
\hline Belém & 14 & $>480$ & 19 \\
\hline Belo Horizonte & 10 & $>480$ & 12 \\
\hline Brasília & 13 & $>480$ & 15 \\
\hline Curitiba & 8 & $>480$ & 14 \\
\hline Fortaleza & 9 & $>480$ & 9 \\
\hline Goiânia & 11 & $>480$ & 15 \\
\hline Porto Alegre & 15 & $>480$ & 18 \\
\hline Recife & 8 & $>480$ & 9 \\
\hline Rio de Janeiro & 12 & $>480$ & 13 \\
\hline Salvador & 10 & $>480$ & 11 \\
\hline São Paulo & 8 & $>480$ & 10 \\
\hline Mediana & 10 & & 13,5 \\
\hline Mínimo & 8 & & 9 \\
\hline Máximo & 15 & & 19 \\
\hline
\end{tabular}

Nas Figuras 1 e 2 reportam-se as IRFs para cada um dos numerários. No primeiro cenário, Figura 1, em que as unidades individuais que não decrescem monotonamente são excluídas, não se observam mudanças significativas no comportamento das $I R F$ s, independentemente de como foram apuradas. Na Figura 2, estão as IRFs setoriais em que todas as $I R F s$ individuais são levadas em consideração no processo de agregação. Como se pode observar, as IRFs não mais decrescem monotonamente para todos os numerários. Gadea e Mayoral (2009) também encontram meias-vidas bastante altas quando usam o estimador MG-CCE com correção de viés, obtendo velocidade de reversão maior que 180 meses em alguns casos.

Essa meia-vida extremamente alta quando obtida pela agregação das IRFs individuais através da média requer investigação adicional, pois, de acordo com Gadea e Mayoral (2009) e Mayoral (2013), a IRF associada à estimação usando os preços relativos agregados é simplesmente o valor esperado das IRFs individuais - portanto, a média das IRFs individuais -, em que pequenas diferenças podem surgir como consequência da transformação logarítmica aplicada aos preços relativos, pois, uma vez que o logaritmo da 
média é diferente da média do logaritmo, as IRFs associadas a cada processo também serão diferentes.

Mayoral e Gadea (2011) especulam, para a sua amostra, o porquê dessa lenta reversão a média. Com dados bastante desagregados, elas mostram que a distribuição da persistência setorial é altamente heterogênea e distorcida para a direita (assimetria alta e positiva), de modo que uma pequena quantidade de setores é responsável pelos altos níveis de persistência observados em nível agregado. Os setores pertencentes à categoria de bens duráveis são apontados como os de mais lenta reversão para a paridade. Por outro lado, aqueles pertencentes ao setor de serviços apresentam mais rápida convergência para a PPC.

Para o conjunto de dados em análise, não é possível identificar os setores com maior persistência. No quadro 1, observa-se que todas as categorias de bens e serviços aparecem pelo menos uma vez como fonte de persistência. Com um conjunto de dados com maior nível de desagregação, talvez fosse possível identificar de forma mais precisa os setores com maior persistência, entretanto, para cidades brasileiras, não estão disponíveis dados com esse nível de desagregação e dimensão temporal satisfatória. ${ }^{22}$

22 Os dados de Mayoral e Gadea (2011) permitem a separação dos preços em 94 setores. Com as atualizações da estrutura de pesos dos bens e serviços, obtidas a partir da Pesquisa de Orçamento Familiar (POF), pertencentes a cesta do IPCA, muitas nomenclaturas são alteradas, de modo que se torna bastante difícil a compatibilização. 
Brasil

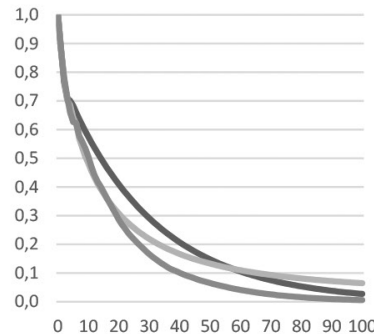

Brasília

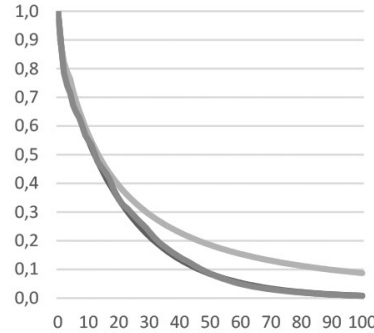

Goiânia

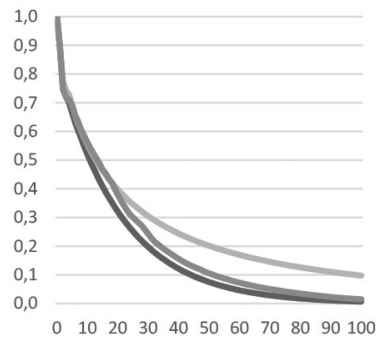

Rio de Janeiro

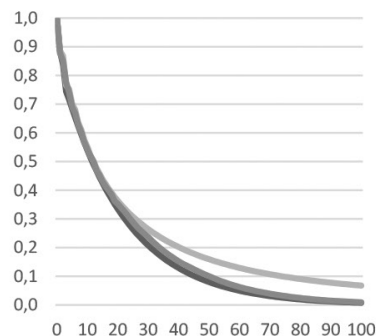

Belém

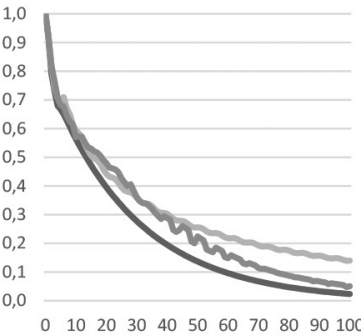

Curitiba

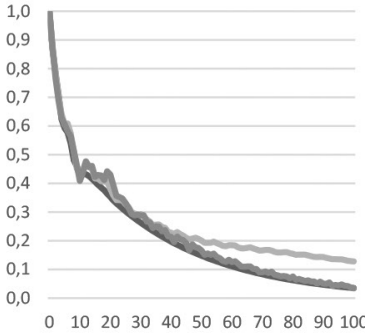

Porto Alegre

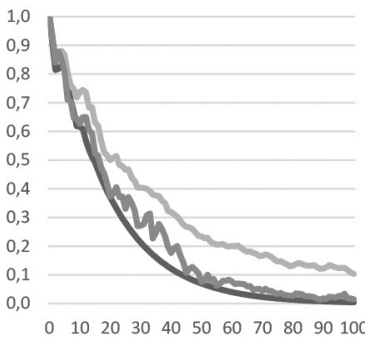

Salvador

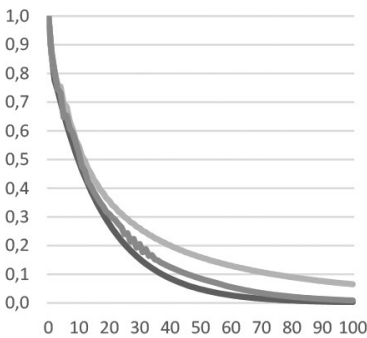

Belo Horizonte

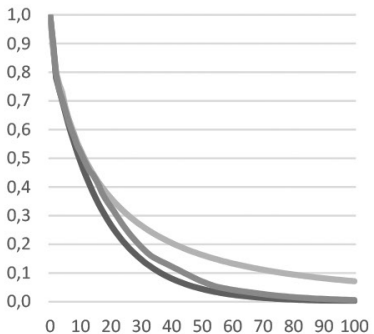

Fortaleza

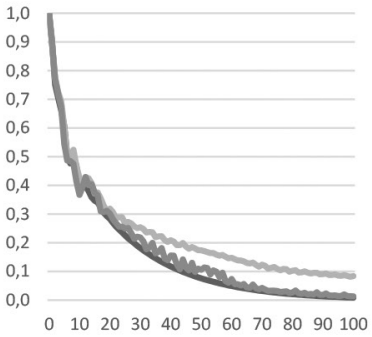

Recife

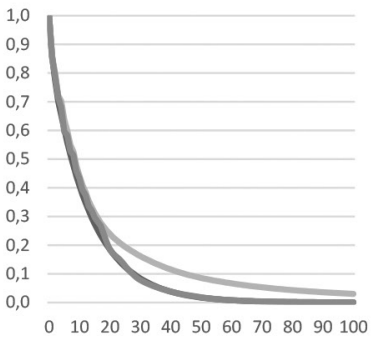

São Paulo

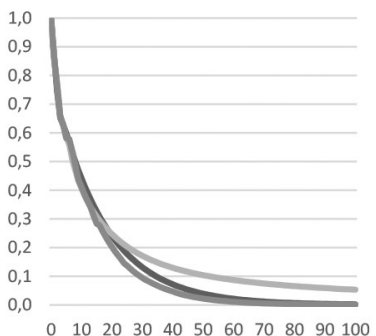

—IRF "Média" —IRF Setorial Média —IRF Setorial Mediana 
Brasil

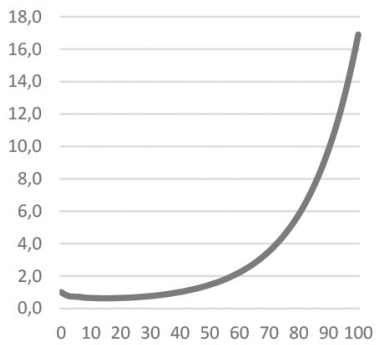

Brasília

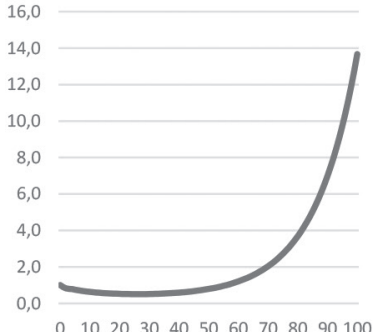

Goiânia

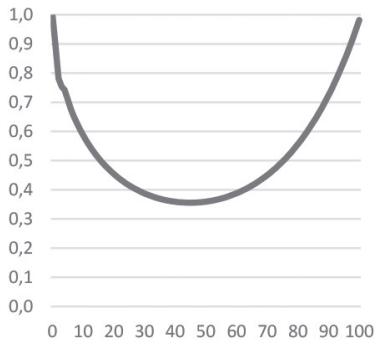

Rio de Janeiro

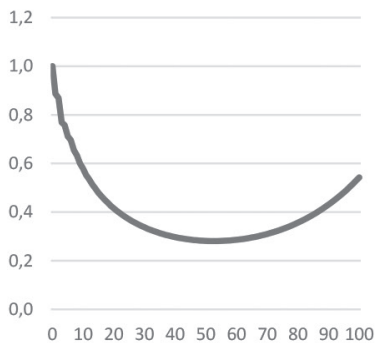

Belém

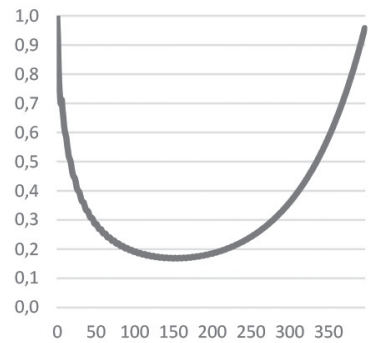

Curitiba

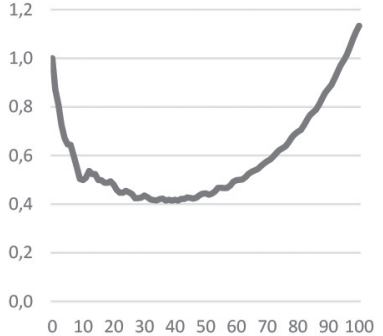

Porto Alegre

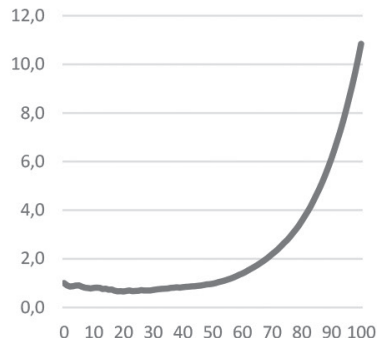

Salvador

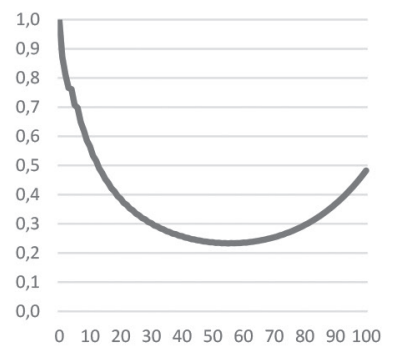

Belo Horizonte

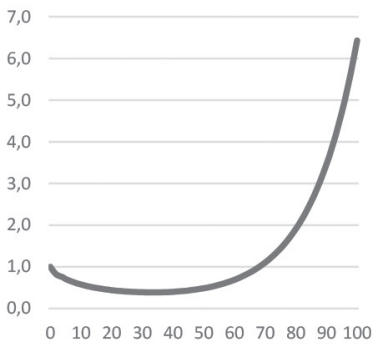

Fortaleza

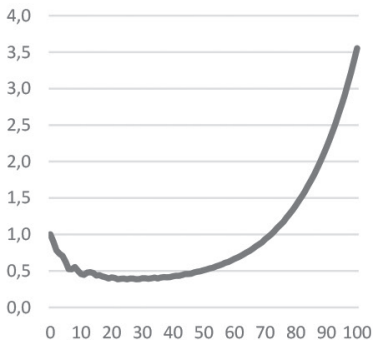

Recife

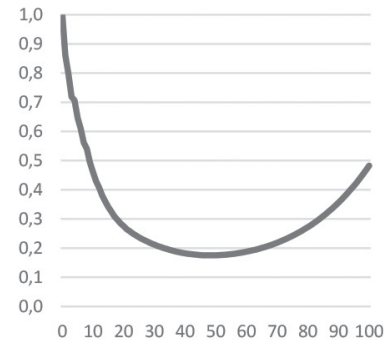

São Paulo

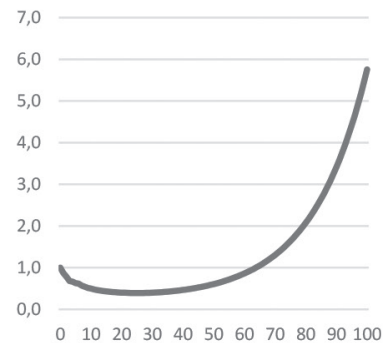

Figura 2 - IRFs com processos autorregressivos persistentes (média) 


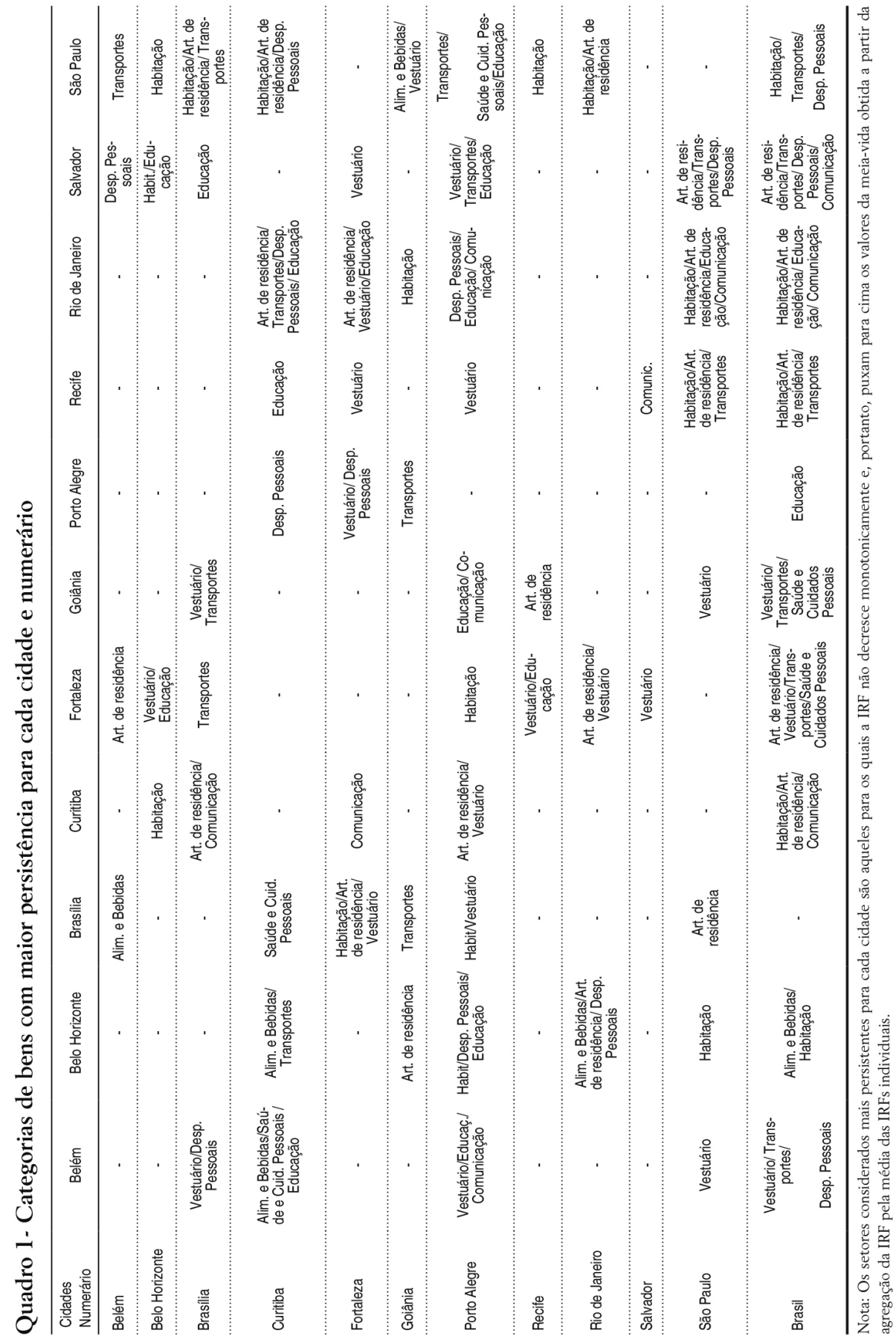


Por meio de regressão quantílica, Mayoral e Gadea (2011) obtêm ainda resultados em consonância com os desenvolvimentos teóricos de Carvalho e Nechio (2011). Dentre eles, destaca-se que variáveis relacionadas à estrutura de mercado dos insumos intermediários e a rigidez de preços de bens finais têm efeito significante sobre a persistência setorial. Já variáveis relacionadas à transacionalidade dos bens não foram significantes.

Por fim, vale destacar que, em suas simulações, Gadea e Mayoral (2009) permitem que os coeficientes autorregressivos sejam no máximo iguais a 1. Já em Mayoral e Gadea (2011), baseadas no fato de que os testes LLC e IPS - que desconsideram a presença de dependência cross-section - rejeitam a nula de raiz unitária em seus dados, ${ }^{23}$ as autoras impõem a restrição de que a soma dos coeficientes autorregressivos sejam menores que $1 \mathrm{em}$ suas estimações. Esse tipo de restrição não é adotado neste trabalho e pode ser uma das razões para o não decaimento exponencial das $I R F$ s setoriais.

No quadro abaixo, tem-se os resultados dos esforços de estimação de meias-vidas existentes para a economia brasileira, bem como resultados de pesquisas que estão no centro do debate da literatura relacionada ao enigma da PPC. Os resultados reportados aqui reforçam aqueles obtidos em IMRR (2005a) e Carvalho e Nechio (2011), com uma meia-vida mediana estimada, à la Gadea e Mayoral (2009), um pouco acima de um ano.

Quadro 2 - Comparação com os resultados da literatura

\begin{tabular}{|c|c|c|c|}
\hline Autores & Metodologia & $\sum_{i=1} \hat{\rho_{J}}$ & Meia-vida \\
\hline Bastos, Ferreira e Arruda (2018) & $\begin{array}{c}\text { GLS factível com correção para os vieses de } \\
\text { Nickell e de agregação temporal }\end{array}$ & 0,8010 & 37,56 \\
\hline Arruda et al. (2015) & Teste Dickey-Fuller Aumentado & 0,9609 & 27,00 \\
\hline Este trabalho & $\begin{array}{c}\text { CCEMG dinâmico com correção jackknife } \\
\text { para o viés de Nickell }\end{array}$ & 0,9458 & 13,50 \\
\hline IMRR (2005a) & MG-CCE & 0,9500 & 11,00 \\
\hline Gadea e Mayoral (2009) ${ }^{c}$ & MG-CCE & - & 28,08 \\
\hline Carvalho e Nechio (2011) & $\begin{array}{l}\text { Resultado quantitativo obtido a partir do mode- } \\
\text { lo parametrizado }\end{array}$ & 0,9600 & 14,00 \\
\hline
\end{tabular}

Nota: ${ }^{a}$ valor médio, inclusive do coeficiente autorregressivo, tendo Brasil como referência. Usando a média e São Paulo como numerário, as meias-vidas médias foram de 19 e 42 meses, respectivamente;

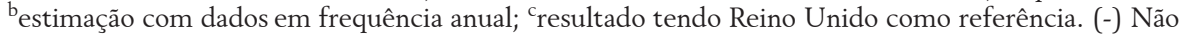
reportou.

${ }^{23}$ Lembre-se que se uma sequência $\left\{p_{t}\right\}$ é estacionária, isto significa que a IRF associada esse processo é tal que $\sum_{k=0}^{\infty} \psi_{k}^{2}<\infty$ e, portanto, a IRF decresce exponencialmente à medida que $k$ cresce. 
Quando confrontado com as meias-vidas computadas para a economia brasileira, pode-se dizer que este resultado está bem abaixo dos reportados até aqui, em Bastos, Ferreira e Arruda (2018) e Arruda et al. (2015), trabalhos que não levam em consideração a questão do viés de heterogeneidade dinâmica.

\section{Considerações Finais}

Este trabalho examina evidências para a economia brasileira que contribuam para a discussão relacionada ao que se convencionou chamar de enigma da PPC. Utilizando a metodologia de estimação para painéis heterogêneos proposta por Chudik e Pesaran (2015), aplicada a informações mensais de preços relativos desagregados por grupos e medidas mais precisas da velocidade de reversão dos desvios da PPC, baseadas em funções de impulso resposta, obtém-se evidências que corroboram os resultados reportados em IMRR (2005a) e Carvalho e Nechio (2011), com meia-vida mediana de 13,5 meses. Pode-se afirmar que esta velocidade de reversão está em conformidade com aquela prevista em modelos teóricos, resultante do impacto de choques monetários e financeiros sobre a taxa de câmbio real, que é de aproximadamente um ano.

Há estimativas anteriores para a economia brasileira em que a heterogeneidade setorial na dinâmica de convergência dos preços relativos não é levada em consideração. Ao se confrontar esta estimação com as obtidas em Bastos, Ferreira e Arruda (2018), observa-se que houve uma significante redução do tempo médio para que um choque unitário sobre os preços relativos se dissipe pela metade, uma vez que os resultados destes autores estão dentro do intervalo-consenso. A meia-vida reportada aqui é também menor que aquela obtida por Arruda et al. (2015), entretanto, a estimação destes, de 27 meses, está também abaixo do intervalo de 3-5 anos de Rogoff (1996).

Em comparação com os resultados da literatura empírica internacional da PPC para cidades, pode-se dizer que o resultado deste trabalho - o resultado obtido pela mediana das IRFs individuais - é substancialmente inferior a grande maioria das meias-vidas reportadas, com reversão a média inferior àquelas obtidas com dados para cidades norte-americanas, mexicanas e es- 
panholas, por exemplo. ${ }^{24}$ Por outro lado, está em sintonia com os de Nath e Sarkar (2014) para cidades australianas, obtidos considerando a presença de mudança estrutural e situados no intervalo de 6,84 a 11,40 meses.

Em adição, tenta-se implementar a correção de viés para o cálculo da meia-vida a partir da IRF sugerida por Gadea e Mayoral (2009). Pode-se dizer que as meias-vidas a partir da agregação pela média das IRFs individuais são, sem exceção, superiores a 480 meses, pois, uma vez que as IRFs setoriais não decaem monotonicamente, o efeito do choque unitário não cai à metade em menos de 480 meses. Este resultado é consequência da alta persistência de algumas unidades individuais para as quais a IRF não decresce monotonamente. Entretanto, a identificação dos setores de maior persistência exigiria o uso de um conjunto de dados com maior desagregação. A investigação deste resultado, muito superior ao intervaloconsenso, é uma interessante agenda de pesquisa futura.

\section{Referências}

Arellano, M.; Bover, O. 1995. "Another Look at the Instrumental-variable Estimation of Error-components Model." Journal of Econometrics 68: 29-52.

Arruda, E.; Barbosa, R. B. Guimarães, D. B.; Castelar, I. 2015. "Price Convergence, Reversal Speed and Purchasing Power Parity: Stylized Facts for Brazilian Cities.” In: XVII Encontro de Economia da Região Sul - XVII ANPEC SUL, Maringá.

Bastos, F. S.; Ferreira, R. T.; Arruda, E. F. 2018. "Speed of Reversion of Deviations of the Purchasing Power Parity for Brazilian Cities.” Revista Brasileira de Economia 72, no.1: 26-40.

Blundell, R.; Bond, S. 1998. "Initial Conditions and Moment Restrictions in Dynamic Panel Data Models." Journal of Econometrics 87: 115-143.

Carvalho, C.; Nechio, F. 2011. "Aggregation and the PPP Puzzle in a Sticky-Price Model." The American Economic Review 101, no. 6: 2391-2424.

Chen, S-S.; Engel, C. 2005. “Does ‘Aggregation Bias’ Explain the PPP Puzzle?” Pacific Economic Review 10, no.1: 49-72.

Chmelarova, V.; Nath, H. K. 2010. "Relative Price Convergence Among US Cities: Does the Choice of Numeraire City Matter?” Journal of Macroeconomics 32: 405-414.

Chudik, A.; Pesaran, M. H. 2015. "Common Correlated Effects Estimation of Heterogeneous Dynamic Panel Data Models with Weakly Exogenous Regressors.” Journal of Econometrics 188, no.2: 393-420.

Dornbusch, R. 1976. "Expectations and Exchange Rate Dynamics.” Journal of Political Economy 84, no.6: 1161-1176.

24 Para maiores detalhes sobre as meias-vidas obtidas na literatura empírica sobre a PPC, ver o Quadro 1 reportado em Bastos, Ferreira e Arruda (2018). 
Everaert, G.; Pozzi, L. 2007. "Bootstrap-based Bias Correction for Dynamic Panels.” Journal of Economic Dynamics and Control 31, no.4: 1160-1184.

Gadea, M. D.; Mayoral, L. 2009. "Aggregation is not Solution: The PPP Puzzle Strikes Back." Journal of Applied Econometrics 24, no. 6: 875-894.

Han, C.; Phillips, P. C. B.; Sul, D. 2017. "Lag Length Selection in Panel Autoregression.” Econometric Reviews 36, no.1-3: 225-240.

Im, K. S.; Pesaran, M. H.; Shin, Y. 2003. "Testing for Unit Roots in Heterogeneous Panels.” Journal of Econometrics 115, no.1: 53-74.

Imbs, J.; Mumtaz, H.; Ravn, M. O.; Rey, H. 2005a. "PPP Strikes Back: Aggregation and the Real Exchange Rate." The Quarterly Journal of Economics 120, no.1: 1-43.

Imbs, J.; Mumtaz, H.; Ravn, M. O.; Rey, H. 2005b. ““Aggregation Bias” Does Explain the PPP Puzzle.” National Bureau of Economic Research Working Paper 11607. Disponível em < http://www.jeanimbs.com/papers2 files/PPPreply.pdf >. Acesso em 07/11/2017.

Kilian, L. 1998. "Small-Sample Confidence Intervals for Impulse Response Functions." The Review of Economics and Statistics 80, no.2: 218-230.

Kilian, L.; Zha, T. 2002. "Quantifying the Uncertainty about the Half-Life of Deviations from PPP.” Journal of Applied Econometrics 17, no.2: 107-125.

Levin, A.; Lin, C.-F.; Chu, C.-S. J. 2002. "Unit Root Tests in Panel Data: Asymptotic and Finite-sample Properties." Journal of Econometrics 108, no.1: 1-24.

Mayoral, L. 2013. "Heterogeneous Dynamics, Aggregation, and the Persistence of Economic Shocks." International Economic Review 54, no.4: 1295-1307.

Mayoral, L.; Gadea, M. D. 2011. "Aggregate Real Exchange Rate Persistence through the Lens of Sectoral Data.” Journal of Monetary Economics 58, no.3: 290-304.

Nath, H. K.; Sarkar, J. 2014. "City Relative Price Dynamics in Australia: Are Structural Breaks Important?" Economic Record 90, no.288: 33-48.

Papell, D. H.; Theodoridis, H. 2001. "The Choice of Numeraire Currency in Panel Tests of Purchasing Power Parity." Journal of Money, Credit and Banking 33: 790-803.

Pesaran, M. H. 2006. "Estimation and Inference in Large Heterogeneous Panels with Multifactor Error Structure." Econometrica 74, no.4: 967-1012.

Pesaran, M. H. 2007. "A Simple Panel Unit Root Test in the Presence of Cross-section Dependence." Journal of Applied Econometrics 22: 265-312.

Pesaran, M. H. 2015. "Testing Weak Cross-Sectional Dependence in Large Panels.” Econometric Reviews 34, no.6-10: 1089-1117.

Pesaran, M. H.; Yamagata, T. 2008. "Testing Slope Homogeneity in Large Panels.” Journal of Econometrics 142: $50-93$.

Rogoff, K. 1996. “The Purchasing Power Parity Puzzle.” Journal of Economic Literature 34: 647-668.

Seong, B.; Morshed, A. K. M. M.; Ahn, S. K. 2006. "Additional Sources of Bias in Half-Life Estimation." Computational Statistics \& Data Analysis 51: 2056-2064.

Simões, O. R.; Marçal, E. F. 2012. “Agregação Temporal e Não-Linearidade Afetam os Testes da Paridade do Poder de Compra: Evidência a Partir de Dados Brasileiros.” Revista Brasileira de Economia 66, no.3: $375-399$. So, B. S.; Shin, D.W. 1999. "Recursive Mean Adjustment in Time Series Inferences.” Statistics and Probability Letters 43: 65-73. 